\title{
On the temperature obtained by oxygen in a state of ebullition, and on the solidification of nitrogen
}

\section{M.S. Wrobelewski}

To cite this article: M.S. Wrobelewski (1884) On the temperature obtained by oxygen in a state of ebullition, and on the solidification of nitrogen, Philosophical Magazine Series 5, 17:104, 158-159, DOI: $10.1080 / 14786448408627497$

To link to this article: http://dx.doi.org/10.1080/14786448408627497

曲 Published online: 29 Apr 2009.

Submit your article to this journal $₫$

Џll Article views: 2

Q View related articles $\sqsubset$ 
the whole mass, at a sufficiently low temperature, is a solid rock of crystallized matter. At the rise of temperature these substances will melt one by one and absorb heat in so doing.-Silliman's American Journal, January 1884.

\section{ON THE TEMPERATURE OBTAINED BY OXYGEN IN A STATE OF EBULLITION, AND ON THE SOLIDIFICATION OF NITROGEN. BY M. S. WROBLEWSKI.}

Of all the gases formerly regarded as permanent, hydrogen alone showed no sign of liquefaction at the temperature of $-136^{\circ} \mathrm{C}$. Even when this gas is submitted, at the above temperature, to a pressure of 150 atmospheres, and the pressure is then suddenly removed, no mist is formed in the tube containing the gas. Evidently, in order to liquefy hydrogen, we must employ a lower temperature than the minimum obtainable by means of liquid ethylene allowed to boil in a vacuum. Of the gases which are more difficult to liquefy than ethylene, and which might be used for the production of a much more intense cold, oxygen appeared to me to be the most serviceable.

The conditions under which the liquefaction of oxygen takes place being already ascertained by my previous researches, it follows that this gas can, at the present time, be liquefied in considerable quantities with great ease. Numberless processes and apparatus are conceivable which would allow of this liquefaction being effected in such a manner that the commercial production of liquid oxygen, if I may so express myself, is only a question of materia] means at the service of the experimenter. Thus since the beginning of October I have used liquid oxygen as a refrigerating agent.

When liquefied in large quantity and allowed to evaporate briskly by the sudden removal of the pressure, oxygen does not solidify like carbonic acid, but it leaves a crystalline residue on the bottom of the ressel in which it was contained in the liquid state and upon the object to be cooled, plunged in the oxygen. I cannot say whether this residue is composed only of crystals of oxygen or whether it arises from possible impurities, since the oxygen which I use in these experiments is prepared from a mixture of potassium chlorate with manganese peroxide. This residue disappears as the temperature commences to rise. If the object to be cooled is contained in a glass tube, the thin layer of this opaque residue is often very troublesome to the observer.

Another circumstance which renders it very difficult to employ liquid oxygen as a cold-producer, is the necessity of using closed apparatus capable of great resistance. Hitherto I have not been able to obtain oxygen in a stable liquid condition under the pressure of one atmosphere. I have had, in consequence, to place the objects to be cooled in the apparatus, which I fill with liquid oxygen, and I can only avail myself of the cold which the boiling oxygen pro- 
duces at the moment when the pressure is removed. As these apparatus are in part constructed of glass, great inconvenience results owing to the constant danger of serious explosions. After several accidents had occurred during these experiments, my assistants and myself, in order to obviate the danger, never worked without masks. But the greatest difficulty to contend with is the short duration of the ebullition of the oxygen, and consequently the too short duration of the cold.

I have attempted to measure the temperature which the boiling oxygen produces. For this purpose I bave adopted a method of thermo-electric measurement which, in addition to being highly sensitive, allows us to record all the sudden changes of temperature of the medium. The indications of the apparatus employed have been compared with those of a hydrogen-thermometer between $+100^{\circ} \mathrm{O}$. and $-130^{\circ} \mathrm{C}$. The nature of the function connecting these indications admits of an extrapolation being made. Reserving the deseription of my method for a future communication, I give here one hundred and eighty-six deyrees below zero $\left(-186^{\circ} \mathrm{C}\right.$.) as the first approximation to the temperature which is produced on the liberation from pressure of liquefied oxygen.

I have submitted nitrogen successfully to the action of this cold. This gas compressed, cooled in boiling oxygen, and then slightly released from pressure, solidifies and falls like snow in crystals of remarkable size._Comptes Rendus, December 31, 1883.

A NEW DEVICE FOR MEAStRING POWER. BY C. F. BRACKETT, PHYSICAL LABORATORY OF THE COLLEGE OF NEW JERSEY.

The following account of a method of measuring the energy expended on or rendered by a dynamo or a magneto-machine will be of interest to those who have to do with the production of electricity in the large way in which it is now employed in the enterprises of the day.

The machine is so supported, on uprights, that it ean freely turn through a small are of a circle whose centre lies in the geometrical axis of the armature. The support may be effected by means of knife-edges or by means of smooth cylindrical bearings, attached directly to the machine or to a cradle on which the machine rests. In the latter case the cradle is made adjustable so that the bottom or floor can be raised or lowered, thus permitting machines of different construction, when placed thereon, to be brought into proper positions as regards axis of revolution and points of support. When the machine, thus mounted, is set in rotation, with closed circuit, the mechanical couple set up between the armature and field magnets tends to malse the latter revolve in the same direction with the armature. The value of the couple, thus operative, and which we desire to know, will be known if we know the value of the couple, 